\title{
Toothbrush Contamination in Family Members
}

\author{
Adolfo Contreras (DDS, MSc, PhD) $)^{1,2}$, Roger Arce (DDS, MSc) $)^{1,2}$, Javier Enrique Botero (DDS, Periodontist, PhD) $)^{1,3}$, \\ Adriana Jaramillo (DDS, MSc) ${ }^{1,2}$, Marisol Betancourt (BSc, MSc) ${ }^{1,4}$
}

\section{ABSTRACT}

Objective: The purpose of this study was to determine the bacterial contamination of toothbrushes in family members. Materials and Methods: One hundred and two healthy subjects were included in this descriptive study. Every individual was examined clinically and microbiologically using the CPITN index and collecting subgingival plaque samples. Each participant received a toothbrush for home use and after one month they returned it to the investigators. All toothbrushes were cultured to determine the presence of periodontopathic bacteria and enteric rods. Wilkoxon signed rank test and $t$ student test $(P \leq 0.05)$ were used to compare differences in the subgingival microbiota and toothbrush contamination and $C P I T N$ index among family members. Results: A high proportion of toothbrushes resulted highly contaminated with enteric rods $(P \leq 0.001)$ compared to the subgingival environment where periodontopathic bacteria were more prevalent. The most frequent microorganisms found in toothbrushes used by parents and children for one month were Enterobacteriaceae, Pseudomonadaceae species ( $>50 \%)$ and Fusobacterium spp (30\%). Conclusions: High levels of enteric rods were commonly detected in toothbrushes used for 1 month among members of the families. These opportunistic organisms may have an important role in oral infections including gingivitis and periodontitis. Monthly replacement or disinfection of the toothbrush can reduce the risk of bacterial transmission/translocation and thus diminish the incidence of biofilm associated oral diseases.

Rev. Clin. Periodoncia Implantol. Rehábil. Oral Vol. 3(1); 24-26, 2010.

Key words: Toothbrush contamination, enteric rods, periodontopathic bacteria, biofilms, Porphyromonas gingivalis, Aggregatibacter actinomycetemcomitans.

\section{INTRODUCTION}

About $95 \%$ of tooth loss in humans are caused by dental caries and periodontal disease. Several microorganisms have been implicated in the pathogenesis and perpetuation of these important oral diseases ${ }^{(1-3)}$. Intra oral transmission (translocation) of microorganisms can occur and therefore infect sites that were previously treated by scaling and root planning. Bacterial transmission between individuals can also occur through kisses or personal contact and even from parents to children ${ }^{(2-4)}$. Several studies have found that cariogenic and periodontopathic bacteria can be transmitted by means of dental instruments(3), dental floss and toothbrush ${ }^{(5-8)}$. The toothbrush can harbour a variety of microorganisms including bacteria, fungi and viruses ${ }^{(9-11)}$, facilitating translocation and transmission of these organisms ${ }^{(12,13)}$. Previously, our laboratory demonstrated that $A$. actinomycetemcomitans and Herpes Simplex virus type I (HSV-1), survived at least for 3 days on toothbrushes and

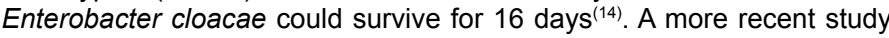
demonstrated that periodontopathic organisms and super-infecting Enterobacteriaceae and Pseudomonadaceae species were cultured from toothbrushes in patients with destructive periodontitis ${ }^{(9)}$ and by this way might facilitate bacterial transmission and translocation. Nonetheless, there is a lack of studies investigating the subgingival microbiota and bacterial contamination of toothbrushes in family members. The purpose of the study was to describe and compare the subgingival microbiota and microbial contamination of toothbrushes after 1 month of home use in children and their parents.

\section{STUDY POPULATION AND METHODOLOGY}

\section{Subjects}

Families attending the dental clinics of the Universidad del Valle (Cali-Colombia) were asked to participate in the study which was approved by the Ethics Committee on Human Research of the Universidad del Valle (Cali-Colombia) and a signed consent was completed. Inclusion parameters included voluntary participation, medically well fitted, children between 5-14 years old and their respective parents. At least one parent was included in the study. Subjects with history of antibiotic use 3 months before subgingival microbial sampling were excluded.

\section{Clinical examination}

A clinical examination by two examiners (AJ, JB) was completed in each individual using the CPITN index according to following protocol: all teeth were evaluated in each patient and only the most affected tooth of each sextant was recorded; if there were less than two teeth, the sextant was considered edentulous and the remaining teeth were included in the next sextant. Periodontal probing was carried out with a periodontal probe UNC-15 (Hu-Friedy $®)$. The index recorded: (0) healthy sextant, (1) bleeding on probing and absence of calculus and plaque, (2) bleeding on probing and plaque and calculus in absence of periodontal pockets, (3) bleeding on probing and 4-5mm periodontal pockets and (4) periodontal pockets of $\geq 6 \mathrm{~mm}$.

\section{Microbiological sampling and processing}

A pooled subgingival microbiological sample (1 site in each sextant) was taken using sterile paper points inserted in either the sulcus or the periodontal pocket for 15 seconds. Supragingival plaque was removed with sterile gauze before sampling. Paper points were placed in vials containing VMGA III and processed within 12 hours sampling. Each participant received 1 toothbrush (Colgate ${ }^{\circ}$ Twister, Colgate ${ }^{\circ}$ junior) and a tube of toothpaste (MFP-Colgate $®$ ) for home use and was instructed to return the toothbrush after 1 month to the investigators. Subgingival microbiota and toothbrush contamination were analyzed using microbial culture techniques for the presence of periodontopathic bacteria according to Doan et al. ${ }^{(15)}$ and Slots ${ }^{(16)}$. Briefly, most samples were processed before 24 hours with a maximum of 48 hours at room atmosphere $\left(25^{\circ} \mathrm{C}\right)$ and immediately incubated in $\mathrm{CO}_{2}$ and anaerobic culture systems. Brucella blood agar medium was incubated at $35^{\circ} \mathrm{C}$ in an anaerobic jar for 7 days. The TSBV medium was incubated in $10 \% \mathrm{CO}_{2}$ in air at $37^{\circ} \mathrm{C}$ for 4 days. Presumptive identification was performed according to methods described by Slots $\&$ Reynolds ${ }^{(17)}$, Rams et al. ${ }^{(18)}$ and by use of commercial micromethod systems for $A$. actinomycetemcomitans, Porphyromonas gingivalis, Prevotella intermedia / nigrescens, Tannerella forsythia, Campylobacter spp, Eubacterium spp, Fusobacterium spp, Peptostreptococcus micros, Eikenella corrodens, Capnocytophaga spp, Dialister pneumosintes, Gram negative enteric rods, $\beta$-hemolytic streptococci, Staphylococci spp and yeasts. Total viable counts (TVC) were defined as the total number of colony forming units obtained on nonselective media plates. Species found on selective media were enumerated and their percentage of TVC was calculated. Special attention was paid to the growth of Gram negative enteric rods and yeasts on TSBV and

\footnotetext{
1. Periodontal Medicine Group, Universidad del Valle, Cali - Colombia.

2. Escuela de Odontología, Universidad del Valle, Cali - Colombia.

3. Facultad de Odontología, Universidad de Antioquia, Medellin - Colombia.

4. Escuela de Bacteriología, Universidad del Valle, Cali - Colombia.

Financial Support: This study was partly supported by a Grant from Colgate-Palmolive (Cali-Colombia).
} 
Brucella agar. Gram negative enteric rods were sub-cultured and colony purified on MacConkey and Cetrimide agar plates and identified using API 20E® system (bioMerieux, Inc., Hazelwood, MO).

\section{Statistical analysis}

Using SPSS (version 9.0) software, Wilkoxon signed rank test was used to compare the subgingival microbiota with the microbiota cultured of toothbrushes in children, fathers and mothers. The $t$ student test was used to find differences in the CPITN index between family members. Statistical significance was assumed when $\mathrm{P} \leq 0.05$.

\section{RESULTS}

Table 1 shows the demographic and clinical description of the families included in the study. A total of 39 families comprising 16 fathers (age 37.6 years old), 39 mothers (age 36.6 years old) and 47 children (age 9.3 years old). There where no differences in the CPITN index between parents but this was higher when compared to their children (2.5 vs $1.3, p \leq 0.001)$. This indicates that most parents had periodontal disease corresponding to slight to moderate attachment loss and pocket formation while, $21.8 \%$ of the parents had severe periodontal disease. In contrast, most children had a slight marginal inflammation (57.4\%).

The frequency detection of peridontopathic bacteria is described in Table 2. The most prevalent microorganism in parents was Fusobacterium spp followed by $P$. intermedia / nigrescens, $P$ gingivalis and $A$. actinomycetemcomitans. In children, the frequency isolated followed a similar pattern and was not statistically significant. Superinfecting bacteria were also detected (>20\%). In contrast, enteric rods corresponding to the Enterobacteriaceae and Pseudomonadaceae family were highly isolated $(62.5 \%-51 \%)$ from toothbrushes (Table 3 ). Periodontopathic bacteria were isolated but in lower frequencies. This indicates that toothbrushes can be contaminated not only by habitual subgingival bacteria but with microorganisms corresponding to Enterics.

When we compared the microbiota from subgingival sites and that found in toothbrushes, the enteric rods were significantly higher $(p \leq 0.01)$ in cultivable proportions in the toothbrushes than in the subgingival samples (Figure 1). In contrast, the proportions of $A$. actinomycetemcomitans, $P$. gingivalis and $P$. intermedia / nigrescens bacteria were higher $(p \leq 0.05)$ in the subgingival habitat that in toothbrushes (Figure 1). This could provide a clue of how enteric rods and other superinfecting bacteria reach the subgingival environment. It was noticed that toothbrushes were kept in the bathroom exposed to household environment. Close contact between the toothbrushes of diverse family members was also revealed (data not shown).

Table 1. Demographic and clinical description of parents and their children.

\begin{tabular}{|c|c|c|c|c|}
\hline & Fathers $(n=16)$ & Mothers $(n=39)$ & Parents $(n=55)^{\star}$ & Children $(n=47)$ \\
\hline Age (mean $\pm S D)$ & $37,6 \pm 8,8$ & $36,6 \pm 9,6$ & $37 \pm 9,3$ & $9,3 \pm 3,2$ \\
\hline Gender & \begin{tabular}{c|c}
$M$ & 16 \\
$F$ & 0
\end{tabular} & $\begin{array}{c}0 \\
39\end{array}$ & $\begin{array}{l}16(20,1 \%) \\
39(79,9 \%)\end{array}$ & $\begin{array}{l}24(51,1 \%) \\
23(48,9 \%)\end{array}$ \\
\hline $\begin{array}{l}\text { CPITN index } \\
(\text { mean } \pm \text { SD) }\end{array}$ & $2,6 \pm 1$ & $2,4 \pm 1,2$ & $2,5 \pm 1,2$ & $1,3 \pm 0,9^{\star *}$ \\
\hline $\begin{array}{l}\text { CPITN } \\
\text { index }(n \%)\end{array}$ & \begin{tabular}{l|c}
0 & 0 \\
1 & $3(18,75 \%)$ \\
2 & $3(18,75 \%)$ \\
3 & $7(43,75 \%)$ \\
4 & $3(18,75 \%)$
\end{tabular} & $\begin{array}{c}0 \\
15(38,4 \%) \\
3(7,6 \%) \\
12(30,7 \%) \\
9(23 \%)\end{array}$ & $\begin{array}{c}0 \\
18(32,7 \%) \\
6(10,9 \%) \\
19(34,5 \%) \\
12(21,8 \%)\end{array}$ & $\begin{array}{c}8(17 \%) \\
27(57,4 \%) \\
4(8,5 \%) \\
8(17 \%) \\
0\end{array}$ \\
\hline
\end{tabular}

${ }^{*}$ Fathers and mothers taken together.

${ }^{* *} p \leq 0,001$ (t student) when compared to parents.
Table 2. Frequency detection of periodontopathic and superinfecting bacteria in parents and their children.

\begin{tabular}{|c|c|c|c|}
\hline Microorganism & $\begin{array}{c}\text { Fathers }(n=16) \\
n(\%)\end{array}$ & $\begin{array}{c}\text { Mothers }(n=39) \\
n(\%)\end{array}$ & $\begin{array}{c}\text { Children }(n=47) \\
n(\%)\end{array}$ \\
\hline $\begin{array}{l}\text { Red Complex } \\
\text { P.gingivalis } \\
\text { T.forsythia }\end{array}$ & $\begin{array}{l}9(56,3) \\
2(12,5)\end{array}$ & $\begin{array}{l}19(48,7) \\
12(30,7)\end{array}$ & $\begin{array}{r}15(31,9) \\
5(10,6)\end{array}$ \\
\hline $\begin{array}{l}\text { Orange Complex } \\
\text { Pintermedia/nigrescens } \\
\text { Fusobacterium spp } \\
\text { P.micros } \\
\text { Campylobacter spp } \\
\text { Eubacterium spp }\end{array}$ & $\begin{array}{c}10(62,5) \\
12(75) \\
5(31,3) \\
6(37,5) \\
6(37,5)\end{array}$ & $\begin{array}{l}17(43,5) \\
35(89,7) \\
12(30,7) \\
19(48,7) \\
20(51)\end{array}$ & $\begin{aligned} &(19,1) \\
& 43(91) \\
& 12(25,5) \\
& 17(36,1) \\
& 24(21)\end{aligned}$ \\
\hline $\begin{array}{l}\text { Green Complex } \\
\text { Aadinamyodemoomians } \\
\text { E.corrodens }\end{array}$ & $\begin{array}{l}5(31,3) \\
4(25)\end{array}$ & $\begin{array}{l}15(38,4) \\
18(46,1)\end{array}$ & $\begin{array}{l}10(20,8) \\
13(27,6)\end{array}$ \\
\hline \begin{tabular}{l}
\multicolumn{1}{c}{ Others } \\
D.pneumosintes \\
Enteric rods
\end{tabular} & $\begin{array}{l}5(31,3) \\
3(18,8)\end{array}$ & $\begin{array}{r}19(48,7) \\
8(20,5)\end{array}$ & $\begin{array}{l}7(14,8) \\
5(10,6)\end{array}$ \\
\hline
\end{tabular}

Table 3. Frequency detection of periodontopathic and superinfecting bacteria isolated from toothbrushes.

\begin{tabular}{|c|c|c|c|}
\hline Microorganism & $\begin{array}{c}\text { Fathers }(n=16) \\
n(\%)\end{array}$ & $\begin{array}{l}\text { Mothers }(n=39) \\
n(\%)\end{array}$ & $\begin{array}{c}\text { Children }(n=47) \\
\text { n (\%) }\end{array}$ \\
\hline $\begin{array}{l}\text { Red Complex } \\
\text { P.gingivalis } \\
\text { T.forsythia }\end{array}$ & $\begin{array}{l}0 \\
0\end{array}$ & $\begin{array}{c}4(10,2) \\
0\end{array}$ & $\begin{array}{c}1(2,12) \\
0\end{array}$ \\
\hline $\begin{array}{l}\text { Orange Complex } \\
\text { Pintermedia/higrescens } \\
\text { Fusobacterium spp } \\
\text { P.micros } \\
\text { Campylobacter spp } \\
\text { Eubacterium spp }\end{array}$ & $\begin{array}{c}0 \\
8(50) \\
1(6,3) \\
2(12,5) \\
5(31,3)\end{array}$ & $\begin{array}{r}5(12,8) \\
12(30,7) \\
1(2,56) \\
5(12,8) \\
7(17,9)\end{array}$ & $\begin{array}{c}2(4,2) \\
16(30) \\
2(4,25) \\
6(63,8) \\
9(19,1)\end{array}$ \\
\hline $\begin{array}{l}\text { Green Complex } \\
\text { Aadinamyoetemoomans } \\
\text { E.corrodens }\end{array}$ & $\begin{array}{c}0 \\
2(12,5)\end{array}$ & $\begin{array}{l}1(2,56) \\
2(5,2)\end{array}$ & $\begin{array}{l}1(2,12) \\
4(8,5)\end{array}$ \\
\hline \begin{tabular}{l}
\multicolumn{1}{c}{ Others } \\
D.pneumosintes \\
Enteric rods
\end{tabular} & $\begin{array}{c}1(6,3) \\
10(62,5)\end{array}$ & $\begin{array}{c}3(7,6) \\
22(56,4)\end{array}$ & $\begin{array}{c}2(4,2) \\
24(51)\end{array}$ \\
\hline
\end{tabular}

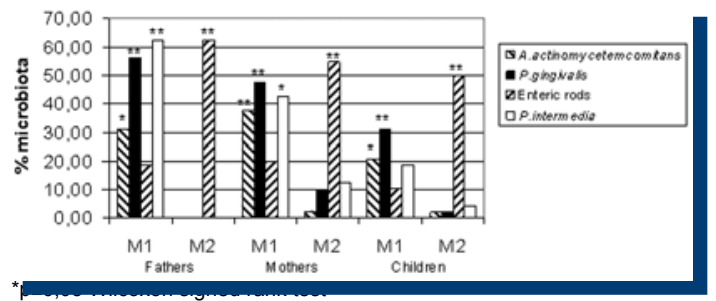

${ }^{* *} \mathrm{p} \leq 0,01$ Wilcoxon signed rank test

M1: subgingival microbiota at first examination

M2: microbiota from toothbrushes used for 1 month

Figure 1. Microbiota from subgingival sities and toothbrushes in parents and their children.

\section{DISCUSSION}

This study demonstrated that toothbrushes used for one month by families resulted contaminated with low proportions of periodontopathic bacteria including $A$. actinomycetemcomitans, $P$. gingivalis and $P$. intermedia / nigrescens. This study may 
implicate toothbrushes in the bacterial transmission / translocation of periodontopathic organisms. In addition, toothbrushes used by most subjects during 1 month and apparently exposed to the bathroom environment resulted heavily contaminated with Enterobacteriaceae and Pseudomonadaceaea species. This contamination does not correlate with the data from subgingival colonization, indicating that the source for toothbrush contamination is not exclusively the subgingival niche. The precise source of these microbial contamination was not determined but we can hypothesize that a relatively short distance from the toilet, the toothbrush storage conditions and the bathroom humidity, facilitated the contamination with Enterobacteriaceae and Pseudomonadaceaea species as it has been previously discussed ${ }^{(19,20)}$.

Important periodontopathic bacteria were found in the present study together with $A$. actinomycetemcomitans, $P$. gingivalis and $P$. intermedia in subgingival niches of parents and children. These microorganisms were generally detected in the periodontal pockets of adults having a CPITN index of 3 . Muller et al. ${ }^{(21)}$ demonstrated that in patients with juvenile periodontitis, $69 \%$ of the toothbrushes examined harboured $A$. actinomycetemcomitans that could remain viable for 24 hours. Our laboratory previously reported ${ }^{(14)}$ that $A$. actinomycetemcomitans could continue viable for at least 3 days in the toothbrush while a superinfecting microorganisms like Enterobacter cloacae remained viable for 16 days. Also it has been demonstrated that in patients with aggressive and chronic periodontitis their toothbrushes were contaminated with periodontopathic and super-infecting bacteria ${ }^{(9)}$, including organisms of the Enterobacteriaceae and Pseudomonadaceaea species. This is in agreement with other studies where the highest levels of microorganism were detected in subjects with periodontitis ${ }^{(5)}$. Consequently, it is important to consider the monitoring of subgingival microbiota in family members to reduce the risk of periodontal breakdown by controlling the presence of periodontopathogens and super-infecting bacteria.

Heavy bacterial contamination of the toothbrush may represent a risk factor in children, immunosupressed patients, pregnant women and elderly people. It has been found that a vigorous toothbrushing might induce transitory bacteremias ${ }^{(22,23)}$ allowing for systemic challenge. The use of toothpaste seems to reduce the counts of microorganisms in the toothbrush ${ }^{(9-14)}$. We recommend using toothpaste containing antibacterial agents for toothbrushing.
Appropriate care of the toothbrush must be instructed to the patients, like storing oral hygiene products in dry environment and away from the toilet. By theses means, we might help reduce the frequency of oral infections including periodontal disease and dental caries ${ }^{(5)}$. The authors consider that an adequate oral hygiene (brushing technique, toothpaste, dental floss, etc) outweighs the risk of a contaminated toothbrush. Teaching patients safe use and storage of oral hygiene elements including toothbrushes should be performed by the dental professionals.

\section{CONCLUSIONS}

A high percentage of home used toothbrushes by children and their parents resulted heavy contaminated with the Enterobacteriaceae and Pseudomonadaceaea microorganisms. This study did not determine the sources for toothbrush contamination. However, closeness to the toilet, aerosols created during toilet flushing and humid environment of the bathroom may facilitate the toothbrush contamination.

A high percentage of children carried important periodontopathic organisms in subgingival plaque samples without still having periodontitis. The microbiota found was in some extent similar between children and parents suggesting that bacterial transmission could have occurred.

It is advisable to replace the toothbrush at least once a month or disinfect it weekly to minimize the bacterial contamination and hence reduce the risk of bacterial transmission and translocation. Toothbrushes must be stored adequately to avoid bristles contact and away from the toilet to reduce the risk of microbial contamination.

\section{ACKNOWLEDGEMENTS}

The authors are grateful with Paulo Gomez, Rodrigo Lañas, Gustavo Valencia for collecting samples and Mrs. Senobia Buritica for laboratory work.

\section{REFERENCES}

1. Asikainen S, Alaluusua S, Saxen L. Recovery of A. actinomycetemcomitans from teeth, tongue, and saliva. J Periodontol. 1991;62(3):203-206.

2. Asikainen S, Chen C, Slots J. Likelihood of transmitting Actinobacillus actinomycetemcomitans and Porphyromonas gingivalis in families with periodontitis. Oral Microbiol Immunol. 1996;11(6):387-394.

3. Papaioannou W, Bollen C, Quirynen. One-stage Full-mouth Disinfection to Overcome Intra-oral Transmission of Periodontopathogens. Anaerobe. 1997;3(3):163-168.

4. Troil-Linden $B$, Torkko $H$, Alaluusua $S$ et al. Periodontal findings in spouses. A clinical, radiographic and microbiological study. J Clin Periodontol. 1995;22(2):93-99.

5. Glass RT, Lare MM. Toothbrush contamination: a potential health risk? Quintessence Int. 1986;17(1):39-42.

6. Glass RT, Jensen HG. More on the contaminated toothbrush: the viral story. Quintessence Int. 1988;19(10):713-716.

7. Glass RT. The infected toothbrush, the infected denture, and transmission of disease: a review. Compendium. 1992;13(7):592, 594, 596-592, 594, 598.

8. Glass RT, Shapiro S. Oral inflammatory disease and the toothbrush. J Ala Dent Assoc. 1993;77(4):12-16.

9. Contreras A., Astudillo M., Daza L. et al. Contaminación microbiana de los cepillos dentales en pacientes con enfermedad periodontal. Revista Estomatología. 2002;10(1):4-14.

10. Falck G, Kjellander J, Schwan A. Recurrence rate of streptococcal pharyngitis related to hygienic measures. Scand J Prim Health Care. 1998;16(1):8-12.

11. Glass RT, Carson SR, Barker RL et al. Detection of HIV proviral DNA on toothbrushes: a preliminary study. J Okla Dent Assoc. 1994;84(3):17-20.

12. Quirynen $M$, Mongardini $C$, Pauwels $M$ et al. One stage full- versus partial-mouth disinfection in the treatment of chronic adult or generalized early-onset periodontitis. II. Long-term impact on microbial load. J Periodontol. 1999;70(6):646-656.
13. Quirynen M, de Soete M, Pauwels $M$ et al. Bacterial survival rate on tooth- and interdental brushes in relation to the use of toothpaste. J Clin Periodontol. 2001;28(12):1106-1114.

14. Gaviría P., Rosales H., Contreras A. Contaminación in Vitro de Cepillos Dentales. Revista Estomatología. 2001;9(2):14-20.

15. Doan N, Contreras A, Flynn J, Morrison J, Slots J. Proficiencies of three anaerobic culture systems for recovering periodontal pathogenic bacteria. Journal of Clinical Microbiology 1999; 37:171-174.

16. Slots J. Rapid identification of important periodontal microorganisms by cultivation. Oral Microbiol Immunol 1986;1:48-55.

17. Slots J, Reynolds HS. Long wave UV light fluorescence for identification of black pigmented Bacteroides spp. J Clin Microbiol 1982:16:1148-1151.

18.Rams TE, Feik D, Young V, Hammond BF, Slots J. Enterococci in human periodontitis. Oral Microbiol Immunol 1992:7:249-252.

19. Barker J, Bloomfield SF. Survival of Salmonella in bathrooms and toilets in domestic homes following salmonellosis. J Appl Microbiol. 2000;89(1):137-144.

20. Kagan LJ, Aiello AE, Larson E. The role of the home environment in the transmission of infectious diseases. J Community Health. 2002;27(4):247-267.

21. Muller HP, Lange DE, MullerRF.Actinobacillus actinomycetemcomitans contamination of toothbrushes from patients harbouring the organism. J Clin Periodontol. 1989;16(6):388-390.

22. Svanberg M. Contamination of toothpaste and toothbrush by Streptococcus mutans. Scand J Dent Res. 1978;86(5):412-414.

23. Sconyers JR, Crawford JJ, Moriarty JD. Relationship of bacteremia to toothbrushing in patients with periodontitis. J Am Dent Assoc. 1973;87(3):616-622. 